\title{
Marital status is an independent prognostic factor in inflammatory breast cancer patients: an analysis of the surveillance, epidemiology, and end results database
}

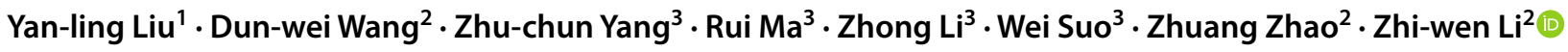

Received: 15 July 2019 / Accepted: 29 July 2019 / Published online: 14 August 2019

(C) The Author(s) 2019

\begin{abstract}
Objectives The aim of this analysis was to study the impact of marital status on inflammatory breast cancer (IBC) patients, as the prognostic impact is yet to be studied in detail.

Methods Data of IBC patients from 2004 to 2010 were sorted out from the database of surveillance, epidemiology, and end results (SEER), and overall survival (OS) rates and breast cancer-specific survival (CSS) rates were compared between a group of married and unmarried patients. The comparison was performed by Kaplan-Meier method with log-rank test, and multivariate survival analysis of CSS and OS was performed using the Cox proportional hazard model.

Results Data of 1342 patients were collected from the SEER database, on an average 52\% of married patients $(n=698$, $52.01 \%)$ and $48 \%$ of unmarried patients $(n=644,47.99 \%)$ for this analysis. Married patients were more likely to be more younger (aged $\leq 56)(52.44 \%$ vs. $43.94 \%)$, white ethnicity ( $83.24 \%$ vs. $71.58 \%)$, HoR positive $(48.28 \%$ vs. $41.61 \%)$, more patients received surgery ( $78.51 \%$ vs. $64.60 \%$ ), chemotherapy (90.69\% vs. $80.12 \%)$ and radiotherapy $(53.44 \%$ vs. $44.41 \%)$ compared to unmarried group, and less likely to be AJCC stage IV (26.22\% vs. 35.40\%) (All $P^{<} 0.05$ ). Married patients had better 5-year CSS $(74.90 \%$ vs. $65.55 \%, P<0.0001)$ and OS rates $(45.43 \%$ vs. $33.11 \%, P<0.0001)$. The multivariate analysis revealed that marital status is an independent prognostic factor, whereas the data of unmarried patients showed worse CSS (HR 1.188; 95\% CI 1.033-1.367; $P=0.016$ ) and OS rates (HR 1.245; 95\% CI 1.090-1.421; $P=0.001$ ). The subgroup analysis further revealed that the OS and CSS rates in the married group were better than the unmarried group, regardless of different AJCC stages.

Conclusion Marital status was an independent prognostic indicator in IBC patients. As the study reveals, the CSS and OS rates of the married patients were better than those of the unmarried patients.
\end{abstract}

Keywords Inflammatory breast cancer $\cdot$ Marital status $\cdot$ SEER $\cdot$ Survival

Yan-ling Liu and Dun-wei Wang have contributed equally to this work.

Electronic supplementary material The online version of this article (https://doi.org/10.1007/s10549-019-05385-8) contains supplementary material, which is available to authorized users.

Zhi-wen Li

prince00111@hotmail.com

1 Department of Oncology, Jilin Cancer Hospital, Changchun 130012, Jilin, China

2 Department of Anesthesiology, First Hospital of Jilin University, Changchun 130021, Jilin, China

3 Department of Radiation Oncology, Jilin Cancer Hospital, Changchun 130012, Jilin, China

\section{Introduction}

Inflammatory breast carcinoma (IBC) is a rare clinico-pathological entity of breast cancer. One to six percent of the breast cancer case comes under IBC [1]. According to the tumor-node metastasis (TNM) breast cancer staging system, IBC is classified as T4d and was clinically characterized by diffusing in duration of the skin with an erysipeloid edge, usually with no underlying mass [2]. IBC is also characterized by rapid progression and higher metastatic potential [3]. The 5-year survival rate of IBC patients is much lower compared to other breast cancer patients [4].

In previous researches, the indicators of clinico-pathological characteristics, such as breast cancer subtypes, AJCC TNM stages, tumor sizes, and treatment strategies, 
were used to predict IBC prognosis and have drawn much attention from the scientists [5-8]. However, social factors are more and more emphasized in the progression of these diseases [9]. It has been revealed that the marital status plays an important role in the prognosis of various carcinomas independently, such as pancreatic carcinoma, prostate carcinoma, lung carcinoma, as well as colorectal carcinoma, where patients in marital status exhibit better survival rates [10-12]. Nevertheless, the comprehension to the effect exerted by marital status on IBC survival rates is still rare.

The surveillance, epidemiology, and end result (SEER) program is supported by the National Cancer Institute (NCI). This program contains research data of 18 different population-based cancer registries that covers $30 \%$ of the United States population [13]. The data of SEER have been extensively used for this study, associated between cancerous survival rates and status of marriage among patients [14-16]. In this paper, we have studied the impact of marital status on the IBC survival rates by analyzing the data from SEER database.

\section{Materials and methods}

\section{Ethical statements}

We signed the SEER Research Data Agreement to access the data, using reference number 16462-Nov2016. The data were obtained by means of research methods in accordance with approved protocols. The data analysis was approved by the Office for Human Research Protection to be non-human subjects, who were researched by the United States Department of Health and Human Services, as they were publicly available and de-identified. Thus, it did not require approval by the institutional review board.

\section{The population of this study}

The subjects were selected and determined using the tool of SEER*State v8.3.5 released on March 6, 2018. The time span of the current study was from 2004 to December 2010. The patients chosen for this study were under the following inclusion criteria: (1) primary female IBC patients aged older than 20; (2) IBC diagnosed in line with the International Classification of Disease for Oncology, Third Edition (ICD-O-3; coded as 8530/3). The exclusion criteria were as follows: (1) patients with multiple primary tumors; (2) patients only clinically diagnosed; (3) patients without some important clinico-pathological information, such as AJCC stage, age when diagnosed, race, marital status, and surgical style; (4) patients died within 3 months after surgery; (5) patients without prognostic data. The rest of subjects were enrolled as the initial cohort of SEER.

\section{Covariables}

We analyzed the patients' characteristics under the following ten parameters: marital status (married, unmarried), age of diagnosis $(\leq 56$, or $>56$ years), race (white, black, or other), Grade (Grade I/II, Grade III/IV, unknown), AJCC stage (IIIA, IIIB, IV), hormone receptor (HoR) (negative, positive, unknown), HER-2 (negative, positive, unknown), surgery (no surgery, partial mastectomy, simple mastectomy, radical mastectomy), chemotherapy(no/ unknown, yes), and radiotherapy (no/unknown, yes). The widowed or single (never married or having a domestic partner) or divorced or separated patients were classified as unmarried. The median age of all included patients was 56 years (range: 22-98 years old). Patients were then subdivided into two groups under age criteria: $<56$ and $\geq 56$ years. Race was again subdivided into white, black, and other (including Asian/Pacific Islander and American Indian/Alaska native). In addition, all chosen cases were restaged in accordance with the 8th AJCC TNM staging classification. The HoR status of the tumor was stratified into HoR estrogen and progesterone-positive (ER +/PR +, ER-/PR + and ER +/PR-) and HoR-negative (ER-/PR-). The definition of ER/PR-positive disease was $1 \%$ or greater cells stain positive [17].

The main objective of this study was to compare the CSS and OS rate. The definition of CSS was the duration from tumor diagnosis to the latest follow-up or date of death due to IBC. And the definition of OS was the duration from tumor diagnosis to the latest follow-up or date of death. Of note, the SEER 2016 submission dataset provided a predetermined cutoff date, which contained the data of death till 2014; therefore, the cutoff date was set as December 31, 2014.

\section{Analyses of statistics}

Baseline continuous and categorical variables were presented as median with range and numbers with percentages, respectively. Meanwhile, clinico-pathological characteristics were compared with Fisher's exact tests or Pearson's $\chi^{2}$. The Kaplan-Meier approach was used to calculate CSS and OS, and the log-rank test was used to compare the variations between different groups. A model of multi-variable COX proportional hazard was established for identification of the independent prognostic factors characterized by the $P$ value lower than 0.05 in the $\log$-rank analyses. Statistical significance was set at twosided $P<0.05$. The analyses of statistics were conducted using SPSS (SPSS Inc., Chicago, USA, version 23), and the survival curves were generated by GraphPad Prism 5 . 


\section{Results}

\section{The characteristics of patients}

We identified 1342 eligible IBC patients diagnosed from 2004 to 2010 in the SEER database with the median followup time of 36 months (range: 0-131 months). Patients were further divided into married group $(n=698,52.01 \%)$ and unmarried group ( $n=644,47.99 \%)$, and the detailed process of screening is shown in Fig. 1. The summary of the baseline features of patients in two groups of marriage status is shown in Table 1. There was a significant difference in the age $(P=0.002)$, race $(P<0.001)$, AJCC stage $(P<0.001)$, HoR $(P=0.033)$, rate of undergone surgery $(P<0.001)$, chemotherapy $(P<0.001)$, and radiotherapy $(P<0.001)$ between married and unmarried groups. Married patients were younger (aged $\leq 56)(52.44 \%$ vs. $43.94 \%)$, white ethnicity ( $83.24 \%$ vs. $71.58 \%$ ), HoR-positive ( $48.28 \%$ vs. $41.61 \%$ ), patients undergone surgery $(78.51 \%$ vs. $64.60 \%)$, chemotherapy ( $90.69 \%$ vs. $80.12 \%)$, radiotherapy $(53.44 \%$ vs. $44.41 \%$ ), and less likely to be in AJCC stage IV (26.22\% vs. $35.40 \%$ ) compared to unmarried group.

\section{Marital status and survival}

There were differences in CSS and OS associated with the status of marriage (both log-rank test $P<0.0001$ ), and the differences are shown in the Kaplan-Meier curves (Fig. 2).
Five-year CSS and OS rate was $47.41 \%$ and $44.39 \%$ in married patients, $35.98 \%$ and $31.52 \%$ in unmarried, respectively. Based on the multivariate log-rank test $(P<0.05)$, a few covariates possessed a significant association with CSS that included all the above-mentioned parameters in Section 'Covariables'. In spite of adjustment by the regression model of COX proportional hazard using these covariables, the results of married status group independently correlated with prognosis and the unmarried group showed significant worse CSS rate than the married group [Hazard ratio (HR)1.188; 95\% Confidence interval (CI) 1.033-1.367; $P=0.016]$ (Table 2). The OS rate for marital status also correlated independently as a prognostic factor, and the unmarried group had worse OS (HR 1.245; 95\% CI 1.090-1.421; $P=0.001]$ (Table 3).

\section{Analysis of the effect of marital status according to AJCC stage in subgroups}

We have analyzed the effects of marital status on IBC survival patients at different AJCC stage subgroups. Figures 3 and 4 show Kaplan-Meier curve of CSS and OS rates in different AJCC stages; regardless of the stage, the CSS and OS survival rates of the married group were better than those of the unmarried group. For AJCC stage IIIA patients in married group, the 5-year CSS and OS rates were $58.27 \%$ and $55.70 \%$, respectively, in comparison with unmarried group which is $51.60 \%$ and $45.21 \%$ (in log-rank test, CSS: $P=0.061$; OS: $P=0.0016$ ). In stage
Fig. 1 Flow chart for screening eligible patients

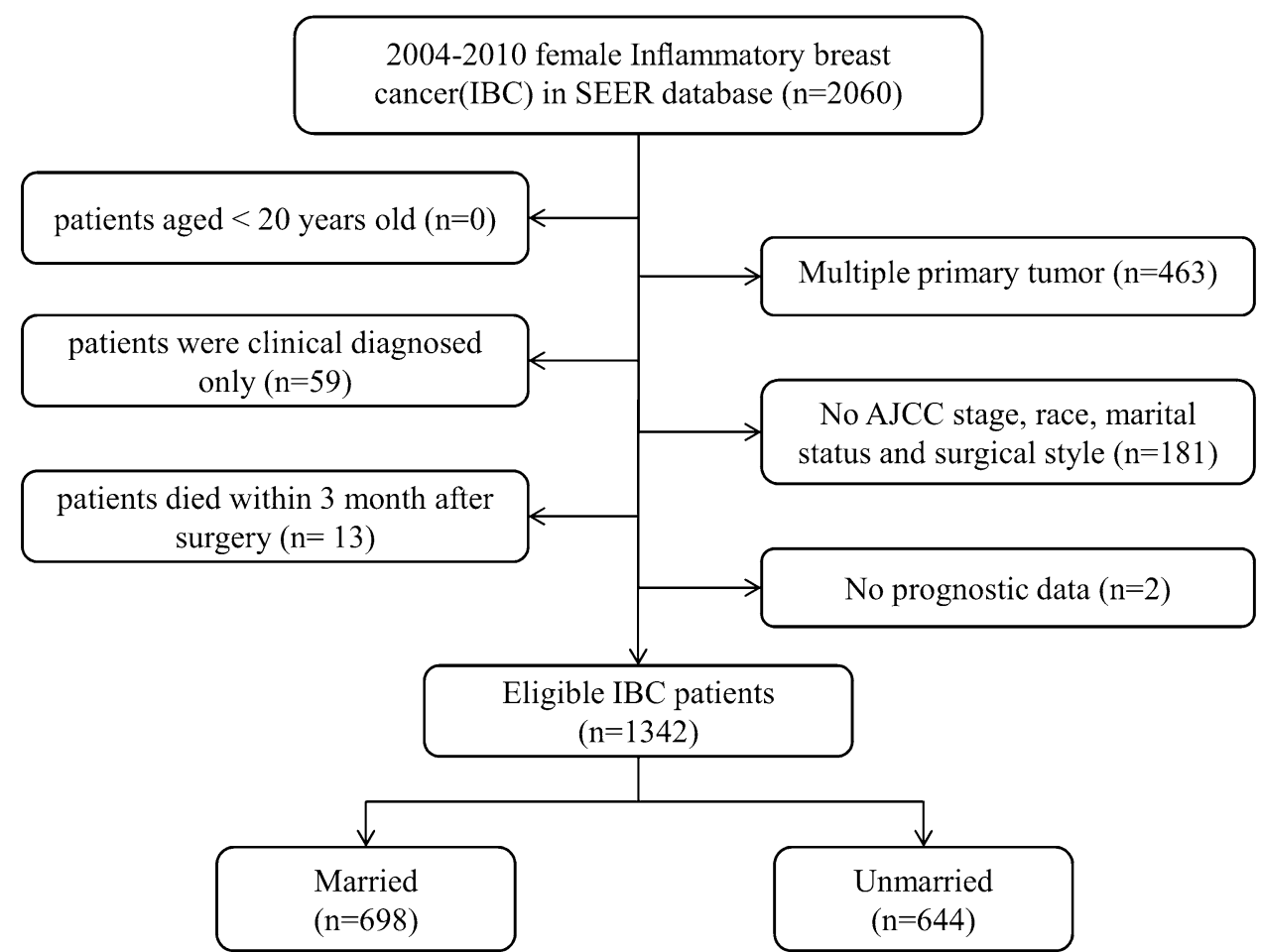


Table 1 Baseline demographic and tumor characteristics of patients in SEER database

\begin{tabular}{|c|c|c|c|c|}
\hline Characteristic & $\begin{array}{l}\text { Total } \\
N(\%)\end{array}$ & $\begin{array}{l}\text { Married } \\
N(\%)\end{array}$ & $\begin{array}{l}\text { Unmarried } \\
N(\%)\end{array}$ & $P$ value $^{+}$ \\
\hline Age & & & & 0.002 \\
\hline$\leq 56$ & $649(48.36 \%)$ & $366(52.44 \%)$ & $283(43.94 \%)$ & \\
\hline$>56$ & $693(51.64 \%)$ & $332(47.56 \%)$ & $361(56.06 \%)$ & \\
\hline Race & & & & $<0.001$ \\
\hline White & $1042(77.65 \%)$ & $581(83.24 \%)$ & $461(71.58 \%)$ & \\
\hline Black & $228(16.99 \%)$ & $78(11.17 \%)$ & $150(23.29 \%)$ & \\
\hline Other* & $72(5.37 \%)$ & $39(5.59 \%)$ & $33(5.12 \%)$ & \\
\hline Grade & & & & 0.160 \\
\hline Grade I/II & $262(19.52 \%)$ & $141(20.20 \%)$ & $121(18.79 \%)$ & \\
\hline Grade III/IV & $773(57.60 \%)$ & $412(59.03 \%)$ & $361(56.06 \%)$ & \\
\hline Unknown & $307(22.88 \%)$ & $145(20.77 \%)$ & $162(25.16 \%)$ & \\
\hline AJCC stage & & & & $<0.001$ \\
\hline IIIA & $706(52.61 \%)$ & $385(55.16 \%)$ & $321(49.84 \%)$ & \\
\hline IIIB & $225(16.77 \%)$ & $130(18.62 \%)$ & $95(14.75 \%)$ & \\
\hline IV & $411(30.63 \%)$ & $183(26.22 \%)$ & $228(35.40 \%)$ & \\
\hline HoR & & & & 0.033 \\
\hline Positive & $605(45.08 \%)$ & $337(48.28 \%)$ & $268(41.61 \%)$ & \\
\hline Negative & $603(44.93 \%)$ & $300(42.98 \%)$ & $303(47.05 \%)$ & \\
\hline Unknown & $134(9.99 \%)$ & $61(8.74 \%)$ & $73(11.34 \%)$ & \\
\hline HER-2 & & & & 0.967 \\
\hline Positive & $40(2.98 \%)$ & $20(2.87 \%)$ & $20(3.11 \%)$ & \\
\hline Negative & $69(5.14 \%)$ & $36(5.16 \%)$ & $33(5.12 \%)$ & \\
\hline Unknown & $1233(91.88 \%)$ & $642(91.98 \%)$ & $591(91.77 \%)$ & \\
\hline Surgery & & & & $<0.001$ \\
\hline No surgery & $378(28.17 \%)$ & $150(21.49 \%)$ & $228(35.40 \%)$ & \\
\hline Partial mastectomy & $62(4.62 \%)$ & $25(3.58 \%)$ & $37(5.75 \%)$ & \\
\hline Simple mastectomy & $127(9.46 \%)$ & $74(10.60 \%)$ & $53(8.23 \%)$ & \\
\hline Radical mastectomy & $775(57.75 \%)$ & $449(64.33 \%)$ & $326(50.62 \%)$ & \\
\hline Chemotherapy & & & & $<0.001$ \\
\hline No/unknown & $193(14.38 \%)$ & $65(9.31 \%)$ & $128(19.88 \%)$ & \\
\hline Yes & $1149(85.62 \%)$ & $633(90.69 \%)$ & $516(80.12 \%)$ & \\
\hline Radiotherapy & & & & $<0.001$ \\
\hline No/unknown & $683(50.89 \%)$ & $325(46.56 \%)$ & $358(55.59 \%)$ & \\
\hline Yes & $659(49.11 \%)$ & $373(53.44 \%)$ & $286(44.41 \%)$ & \\
\hline
\end{tabular}

$H o R$ hormone receptor

* Other includes American Indian/Alaska native, Asian/Pacific Islander, and unknown

+ The comparison results between married and unmarried group
IIIB patients, the five-year CSS and OS rates were 50.84\% and $42.81 \%$ in married patients and $34.92 \%$ and $33.83 \%$ for unmarried patients(in log-rank test, CSS: $P=0.015$; OS: $P=0.11$ ). The stage IV patients also showed better 5-year CSS and OS rates in married group which is $22.48 \%$ and $21.86 \%$ compared to the percentage of unmarried patients that is $13.57 \%$ and $11.06 \%$ (in log-rank test, CSS: $P=0.0011$; OS: $P<0.0001)$.

\section{Discussions}

This SEER analysis is the first study to specifically examine whether marital status has a significant impact on the survival rate of IBC patients. On analyzing the case history of 1342 IBC patients, we observed a remarkable higher risk of death in unmarried patients than married patients. After the control of demographic tumor characteristics and 
A

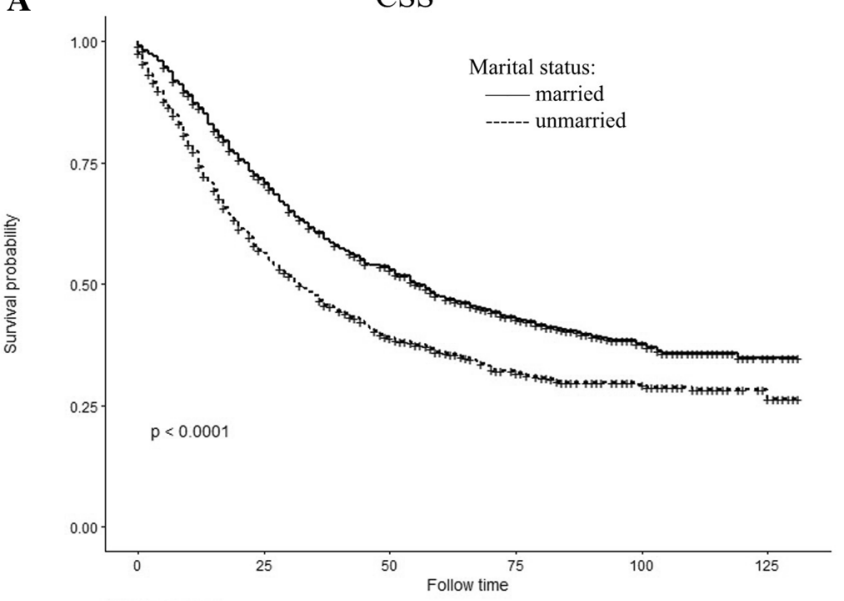

B

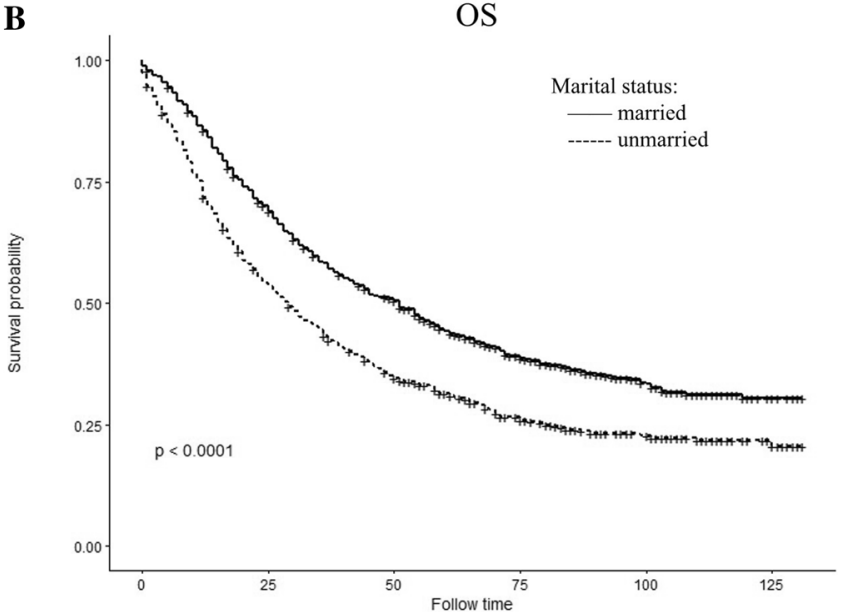

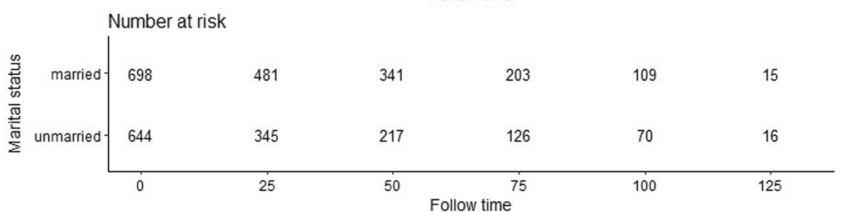

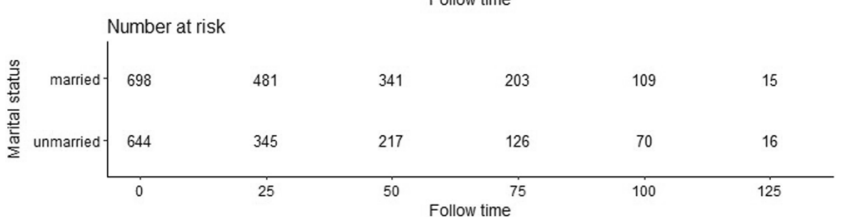

Fig. 2 Kaplan-Meier survival curves of cancer-specific survival (a) and overall survival (b) in different marital status

treatment methods, unmarried patients had $18.8 \%$ higher risk of cancer-specific deaths and $24.5 \%$ higher risk of overall deaths compared to married patients with IBC.

There are some reports on the association between the prognosis of breast carcinoma and marital status [14, 18-21]. Two studies from M.D. Anderson Hospital did not detect marital status had a significantly effect on survival when stage and the other variables were included. The differences in survival rate in all the covariables always remained higher in married group $[18,19]$. To add on to the evidence, many scholars have found that the marital status has a significant impact on the prognosis of other type of breast cancer [20,21]. Adekolujo et al. found that unmarried females with breast cancer were at greater risk for stage IV disease on diagnosis and more poor outcomes compared to married females [20]. Hinyard L also found that the probability of late-stage diagnosis among unmarried female patients was 1.18 -fold higher than that of married female patients. In the analysis after adjustment, unmarried women were more likely to die of breast cancer and more likely to die of all causes than married women, irrespective of all AJCC stages [21]. The results of these studies basically conclude that the prognosis is better and staging is earlier in married patients than that of unmarried patients, which is basically consistent in all the results of our studies. Some scholars even found that the survival benefit associated with marriage was larger than the published survival benefit of chemotherapy [14].

The influence of marital status on prognosis may be related to tumor stage, proportion of patients receiving treatment, and social support [14, 20-22]. Our study found that married patients who were in earlier tumor stage were younger and had significantly higher proportion of white race and HoR-positive. In addition, we found that the likelihood of receiving surgeries, chemotherapy, and radiotherapy among unmarried subjects was lower than married ones. Hershman et al. also stated that unmarried subjects tend to postpone the onset of adjuvant chemotherapeutic treatment after receiving surgeries of breast carcinoma, which resulted in increased mortality rate [23]. This partly explains why unmarried patients have poorer prognosis.

However, after the adjustment of these factors, multivariate analysis still found that marital status was an independent prognostic risk factor for patients with IBC. Thus, there are deeper reasons to how the marital status affects the prognosis of IBC patients. Patients who are unmarried lack the support and care from spouses, thus often suffer from distressed psychological state and indulge in bad habits, (smoking and excessive drinking) which cause development of tumor and under-treatment of diseases [24-26]. The patients in marital status are supported economically and encouraged by their spouses, which conduce to the acceptance for adjuvant therapies and surgeries, thus leading to the differentiation to a certain degree $[27,28]$.

Our study is interpreted with caution due to the limited access of the SEER database. First, the information of marriage status obtained from the database was collected when patients were diagnosed of IBC, which could have been possibly changed during the time span of followups, thus probably affecting the final results. Second, no accurate details of marriage were provided by the database 
Table 2 Univariate and multivariate survival analysis of CSS in inflammatory breast cancer patients

\begin{tabular}{|c|c|c|c|c|c|}
\hline \multirow[t]{2}{*}{ Characteristic } & \multicolumn{2}{|c|}{ Univariate analysis } & \multicolumn{3}{|c|}{ Multivariate analysis } \\
\hline & Log-rank $\chi^{2}$ & $P$ value & $\overline{\mathrm{HR}}$ & $95 \% \mathrm{CI}$ & $P$ value \\
\hline Marital status & 24.239 & $<0.001$ & & & \\
\hline Married & & & Reference & & \\
\hline Unmarried & & & 1.188 & $1.033-1.367$ & 0.016 \\
\hline Age & 2.685 & 0.101 & & & NI \\
\hline$\leq 56$ & & & & & \\
\hline$>56$ & & & & & \\
\hline Race & 47.365 & $<0.001$ & & & $<0.001$ \\
\hline White & & & Reference & & \\
\hline Black & & & 1.663 & $1.398-1.979$ & $<0.001$ \\
\hline Other* & & & 0.781 & $0.551-1.106$ & 0.164 \\
\hline Grade & 14.508 & 0.001 & & & 0.041 \\
\hline Grade I/II & & & Reference & & \\
\hline Grade III/IV & & & 1.138 & $0.937-1.381$ & 0.191 \\
\hline Unknown & & & 0.914 & $0.729-1.147$ & 0.437 \\
\hline AJCC stage & 280.068 & $<0.001$ & & & $<0.001$ \\
\hline IIIA & & & Reference & & \\
\hline IIIB & & & 1.479 & $1.209-1.810$ & $<0.001$ \\
\hline IV & & & 2.624 & $2.212-3.113$ & $<0.001$ \\
\hline HOR & 68.344 & $<0.001$ & & & $<0.001$ \\
\hline Positive & & & Reference & & \\
\hline Negative & & & 1.809 & $1.550-2.111$ & $<0.001$ \\
\hline Unknown & & & 2.185 & $1.728-2.763$ & $<0.001$ \\
\hline HER-2 & 7.187 & 0.028 & & & 0.006 \\
\hline Positive & & & Reference & & \\
\hline Negative & & & 2.208 & $1.114-4.373$ & 0.023 \\
\hline Unknown & & & 2.588 & $1.420-4.715$ & 0.002 \\
\hline Surgery & 318.410 & $<0.001$ & & & \\
\hline No surgery & & & Reference & & \\
\hline Partial mastectomy & & & 0.493 & $0.350-0.695$ & $<0.001$ \\
\hline Simple mastectomy & & & 0.495 & $0.375-0.653$ & $<0.001$ \\
\hline Radical mastectomy & & & 0.484 & $0.401-0.585$ & $<0.001$ \\
\hline Chemotherapy & 64.214 & $<0.001$ & & & \\
\hline No/unknown & & & Reference & & \\
\hline Yes & & & 0.563 & $0.462-0.687$ & $<0.001$ \\
\hline Radiotherapy & 47.991 & $<0.001$ & & & \\
\hline No/unknown & & & Reference & & \\
\hline Yes & & & 0.890 & $0.765-1.036$ & 0.133 \\
\hline
\end{tabular}

SEER 2004-2010 $(n=1342)$

$H o R$ hormone receptor

*Other includes American Indian/Alaska native, Asian/Pacific Islander, and unknown of SEER, which was capable of influencing the results of survival rates [29]. Third, the therapeutic details are limited in the database of SEER, especially radiotherapy and chemotherapy. In spite of the above-mentioned constraints, it is indicated by the current study that the status of marriage has a significant impact on the survival of IBC. The significance of this work is in studying the essential and continuous effects exhibited by the marital characteristics, especially social supports, after detecting and treating carcinoma and the survival rates. The probability of curing unmarried patients has been remarkably increased by investment in social support intervention. Further investigation in analysis such as cost and benefits and the intervention approaches that are innovative and cost-effective could be an effective way of improving carcinoma prognosis of unmarried patients. 
Table 3 Univariate and multivariate survival analysis of OS in inflammatory breast cancer patients

\begin{tabular}{|c|c|c|c|c|c|}
\hline \multirow[t]{2}{*}{ Characteristic } & \multicolumn{2}{|c|}{ Univariate analysis } & \multicolumn{3}{|c|}{ Multivariate analysis } \\
\hline & Log-rank $\chi^{2}$ & $P$ value & HR & $95 \% \mathrm{CI}$ & $P$ value \\
\hline Marital status & 34.333 & $<0.001$ & & & \\
\hline Married & & & Reference & & \\
\hline Unmarried & & & 1.245 & $1.090-1.421$ & 0.001 \\
\hline Age & 12.079 & 0.001 & & & \\
\hline$\leq 56$ & & & Reference & & \\
\hline$>56$ & & & 1.061 & $0.926-1.215$ & 0.395 \\
\hline Race & 50.956 & $<0.001$ & & & $<0.001$ \\
\hline White & & & Reference & & \\
\hline Black & & & 1.709 & $1.448-2.017$ & $<0.001$ \\
\hline Other* & & & 0.857 & $0.624-1.178$ & 0.341 \\
\hline Grade & 10.623 & 0.005 & & & 0.055 \\
\hline Grade I/II & & & Reference & & \\
\hline Grade III/IV & & & 1.089 & $0.911-1.302$ & 0.348 \\
\hline Unknown & & & 0.888 & $0.719-1.096$ & 0.267 \\
\hline AJCC stage & 267.703 & $<0.001$ & & & $<0.001$ \\
\hline IIIA & & & Reference & & \\
\hline IIIB & & & 1.448 & $1.200-1.748$ & $<0.001$ \\
\hline IV & & & 2.399 & $2.040-2.820$ & $<0.001$ \\
\hline HOR & 54.232 & $<0.001$ & & & $<0.001$ \\
\hline Positive & & & Reference & & \\
\hline Negative & & & 1.656 & $1.433-1.914$ & $<0.001$ \\
\hline Unknown & & & 1.981 & $1.585-2.476$ & $<0.001$ \\
\hline HER-2 & 6.871 & 0.032 & & & 0.008 \\
\hline Positive & & & Reference & & \\
\hline Negative & & & 1.920 & $1.019-3.619$ & 0.044 \\
\hline Unknown & & & 2.291 & $1.319-3.981$ & 0.003 \\
\hline Surgery & 29.854 & $<0.001$ & & & \\
\hline No surgery & & & Reference & & \\
\hline Partial mastectomy & & & 0.472 & $0.339-0.657$ & $<0.001$ \\
\hline Simple mastectomy & & & 0.508 & $0.391-0.661$ & $<0.001$ \\
\hline Radical mastectomy & & & 0.505 & $0.422-0.604$ & $<0.001$ \\
\hline Chemotherapy & 114.104 & $<0.001$ & & & \\
\hline No/unknown & & & Reference & & \\
\hline Yes & & & 0.499 & $0.415-0.600$ & $<0.001$ \\
\hline Radiotherapy & 59.602 & $<0.001$ & & & \\
\hline No/unknown & & & Reference & & \\
\hline Yes & & & 0.864 & $0.748-0.996$ & 0.045 \\
\hline
\end{tabular}

SEER 2004-2010 $(n=1342)$

HoR hormone receptor

*Other includes American Indian/Alaska native, Asian/Pacific Islander, and unknown 


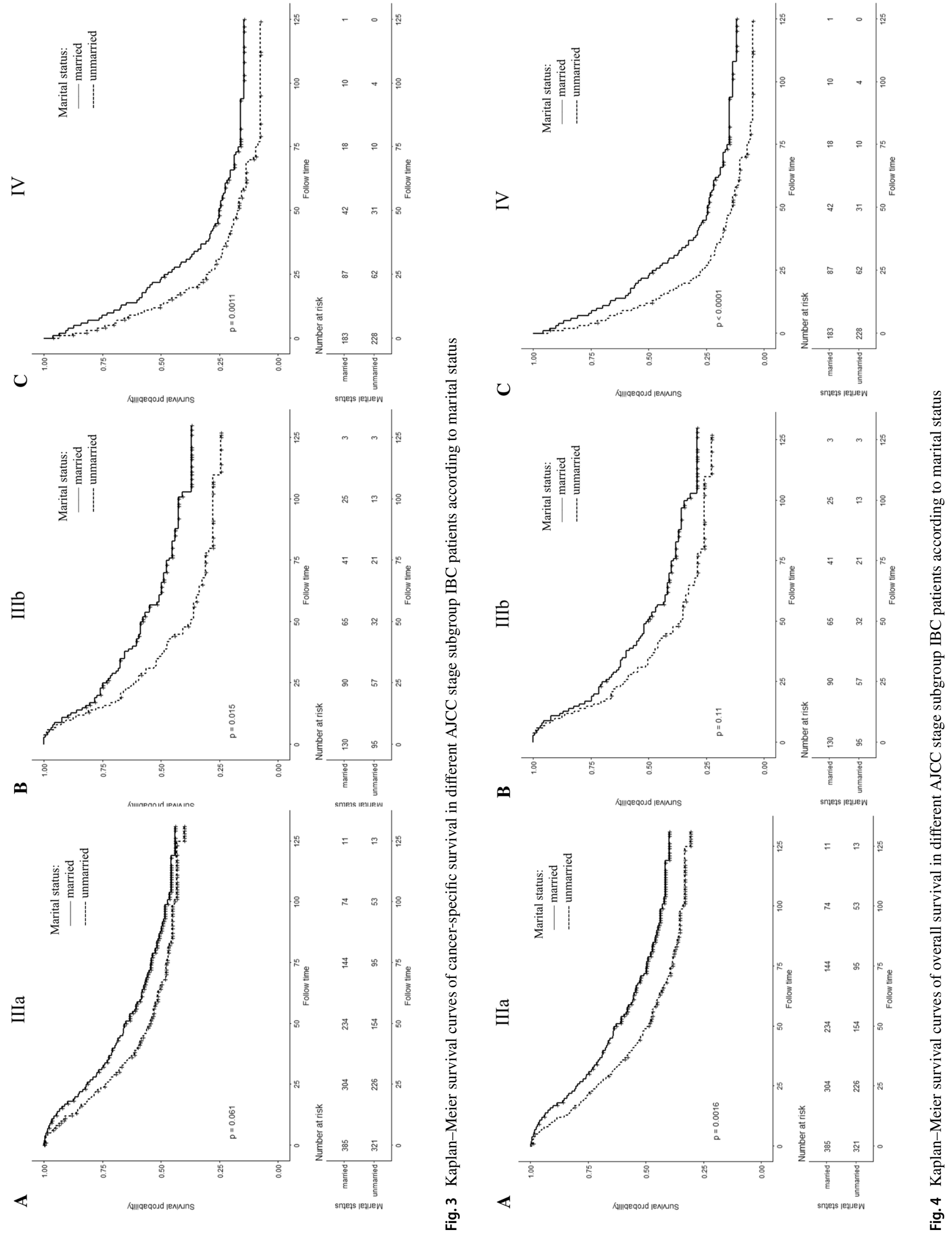




\section{Conclusion}

To conclude, our study has revealed that marital status is an independent prognostic indicator of IBC patients and it has a significant impact to extend the CSS and OS rate. According to our analysis on different variables between married and unmarried patients, married patients have better CSS and OS than unmarried patients. Going forward, further analysis on the data of married patients can throw more light on the reasons for their extended CSS and OS, which could help the unmarried patients to fight against the IBC and increase their CSS and OS.

Data availability The data that support the findings of this study are available from SEER but restrictions apply to the availability of these data, which were used under a signed SEER Research Data agreement for the current study, and so are not publicly available. Data are however available from the authors upon reasonable request and with permission of SEER

\section{Compliance with ethical standards}

Conflict of interest The authors declare that they have no conflict of interest.

Ethical approval This article does not contain any studies with human participants or animals performed by any of the authors.

Informed consent As this study is based on a publicly available database without identifying patient information, informed consent was not needed.

Open Access This article is distributed under the terms of the Creative Commons Attribution 4.0 International License (http://creativecommons.org/licenses/by/4.0/), which permits unrestricted use, distribution, and reproduction in any medium, provided you give appropriate credit to the original author(s) and the source, provide a link to the Creative Commons license, and indicate if changes were made.

\section{References}

1. Hance KW, Anderson WF, Devesa SS, Young HA, Levine PH (2005) Trends in inflammatory breast carcinoma incidence and survival: the surveillance, epidemiology, and end results program at the National Cancer Institute. J Natl Cancer Inst 97(13):966975. https://doi.org/10.1093/jnci/dji172

2. Kleer CG, van Golen KL, Merajver SD (2000) Molecular biology of breast cancer metastasis. Inflammatory breast cancer: clinical syndrome and molecular determinants. Breast Cancer Res 2(6):423-429. https://doi.org/10.1186/bcr89

3. Cristofanilli M, Buzdar AU, Hortobagyi GN (2003) Update on the management of inflammatory breast cancer. Oncologist $8(2): 141-148$

4. Wingo PA, Jamison PM, Young JL, Gargiullo P (2004) Population-based statistics for women diagnosed with inflammatory breast cancer (United States). Cancer Causes Control 15(3):321328. https://doi.org/10.1023/b:caco.0000024222.61114.18
5. Moslehi R, Freedman E, Zeinomar N, Veneroso C, Levine PH (2016) Importance of hereditary and selected environmental risk factors in the etiology of inflammatory breast cancer: a case-comparison study. BMC Cancer 16:334. https://doi.org/10.1186/s1288 5-016-2369-z

6. Le MG, Arriagada R, Bahi J, Pfeiffer F, Cammoun M, Tabbane F, Rubino C (2006) Are risk factors for breast cancer similar in women with inflammatory breast cancer and in those with non-inflammatory breast cancer? Breast (Edinburgh, Scotland) 15(3):355-362. https://doi.org/10.1016/j.breast.2005.08.018

7. Schairer C, Li Y, Frawley P, Graubard BI, Wellman RD, Buist DS, Kerlikowske K, Onega TL, Anderson WF, Miglioretti DL (2013) Risk factors for inflammatory breast cancer and other invasive breast cancers. J Natl Cancer Inst 105(18):1373-1384. https://doi. org/10.1093/jnci/djt206

8. Wu SG, Zhang WW, Wang J, Dong Y, Sun JY, Chen YX, He ZY (2019) Inflammatory breast cancer outcomes by breast cancer subtype: a population-based study. Future Oncol (London, England) 15(5):507-516. https://doi.org/10.2217/fon-2018-0677

9. Adler RH (2009) Engel's biopsychosocial model is still relevant today. J Psychosom Res 67(6):607-611. https://doi.org/10.1016/j. jpsychores.2009.08.008

10. Li Q, Gan L, Liang L, Li X, Cai S (2015) The influence of marital status on stage at diagnosis and survival of patients with colorectal cancer. Oncotarget 6(9):7339-7347. https://doi.org/10.18632/ oncotarget. 3129

11. Wu Y, Ai Z, Xu G (2017) Marital status and survival in patients with non-small cell lung cancer: an analysis of 70006 patients in the SEER database. Oncotarget 8(61):103518-103534. https://doi. org/10.18632/oncotarget.21568

12. Wang XD, Qian JJ, Bai DS, Li ZN, Jiang GQ, Yao J (2016) Marital status independently predicts pancreatic cancer survival in patients treated with surgical resection: an analysis of the SEER database. Oncotarget 7(17):24880-24887. https://doi. org/10.18632/oncotarget.8467

13. Duggan MA, Anderson WF, Altekruse S, Penberthy L, Sherman ME (2016) The surveillance, epidemiology, and end results (SEER) program and pathology: toward strengthening the critical relationship. Am J Surg Pathol 40(12):e94-e102. https://doi. org/10.1097/pas.0000000000000749

14. Aizer AA, Chen MH, McCarthy EP, Mendu ML, Koo S, Wilhite TJ, Graham PL, Choueiri TK, Hoffman KE, Martin NE, Hu JC, Nguyen PL (2013) Marital status and survival in patients with cancer. J Clin Oncol 31(31):3869-3876. https://doi.org/10.1200/ jco.2013.49.6489

15. Zhou H, Zhang Y, Song Y, Tan W, Qiu Z, Li S, Chen Q, Gao S (2017) Marital status is an independent prognostic factor for pancreatic neuroendocrine tumors patients: an analysis of the surveillance, epidemiology, and end results (SEER) database. Clin Res Hepatol Gastroenterol 41(4):476-486. https://doi.org/10.1016/j. clinre.2017.02.008

16. Chen Z, Cui J, Dai W, Yang H, He Y, Song X (2018) Influence of marital status on small intestinal adenocarcinoma survival: an analysis of the surveillance, epidemiology, and end results (SEER) database. Cancer Manag Res 10:5667-5676. https://doi. org/10.2147/cmar.s177430

17. Howlader N, Chen VW, Ries LA, Loch MM, Lee R, DeSantis C, Lin CC, Ruhl J, Cronin KA (2014) Overview of breast cancer collaborative stage data items-their definitions, quality, usage, and clinical implications: a review of SEER data for 2004-2010. Cancer 120(Suppl 23):3771-3780. https://doi.org/10.1002/cncr.29059

18. Neale AV, Tilley BC (1982) Vernon SW (1986) Marital status, delay in seeking treatment and survival from breast cancer. Soc Sci Med 23(3):305-312

19. Neale AV (1994) Racial and marital status influences on 10 year survival from breast cancer. J Clin Epidemiol 47(5):475-483 
20. Adekolujo OS, Tadisina S, Koduru U, Gernand J, Smith SJ, Kakarala RR (2017) Impact of marital status on tumor stage at diagnosis and on survival in male breast cancer. Am J Men's Health 11(4):1190-1199. https://doi.org/10.1177/1557988316 669044

21. Hinyard L, Wirth LS, Clancy JM, Schwartz T (2017) The effect of marital status on breast cancer-related outcomes in women under 65: a SEER database analysis. Breast (Edinburgh, Scotland) 32:13-17. https://doi.org/10.1016/j.breast.2016.12.008

22. Wang X, Cao W, Zheng C, Hu W, Liu C (2018) Marital status and survival in patients with rectal cancer: an analysis of the surveillance, epidemiology and end results (SEER) database. Cancer Epidemiol 54:119-124. https://doi.org/10.1016/j.canep 2018.04.007

23. Hershman DL, Wang X, McBride R, Jacobson JS, Grann VR, Neugut AI (2006) Delay of adjuvant chemotherapy initiation following breast cancer surgery among elderly women. Breast Cancer Res Treat 99(3):313-321. https://doi.org/10.1007/s1054 9-006-9206-Z

24. Surman M, Janik ME (2017) Stress and its molecular consequences in cancer progression. Postepy Hig Med Dosw (Online) 71:485-499

25. Goldzweig G, Andritsch E, Hubert A, Brenner B, Walach N, Perry S, Baider L (2010) Psychological distress among male patients and male spouses: what do oncologists need to know? Ann Oncol 21(4):877-883. https://doi.org/10.1093/annonc/mdp398
26. Goldzweig G, Andritsch E, Hubert A, Walach N, Perry S, Brenner $B$, Baider L (2009) How relevant is marital status and gender variables in coping with colorectal cancer? A sample of middle-aged and older cancer survivors. Psycho-oncology 18(8):866-874. https ://doi.org/10.1002/pon.1499

27. De Luca R, Dorangricchia P, Salerno L, Lo Coco G, Cicero $\mathrm{G}$ (2017) The role of couples' attachment styles in patients' adjustment to cancer. Oncology 92(6):325-334. https://doi. org/10.1159/000455956

28. Kanters AE, Morris AM, Abrahamse PH, Mody L, Suwanabol PA (2018) The effect of peer support on colorectal cancer patients' adherence to guideline-concordant multidisciplinary care. Dis Colon Rectum 61(7):817-823. https://doi.org/10.1097/dcr.00000 00000001067

29. Jaremka LM, Glaser R, Malarkey WB, Kiecolt-Glaser JK (2013) Marital distress prospectively predicts poorer cellular immune function. Psychoneuroendocrinology 38(11):2713-2719. https:// doi.org/10.1016/j.psyneuen.2013.06.031

Publisher's Note Springer Nature remains neutral with regard to jurisdictional claims in published maps and institutional affiliations. 